Original article

\title{
Malignant testicular germ cell tumors in children and adolescents: The AIEOP (Associazione Italiana Ematologia Oncologia Pediatrica) protocol
}

\author{
Monica Terenziani, M.D. ${ }^{\mathrm{a}, *}$, Maria D. De Pasquale, M.D. ${ }^{\mathrm{b}}$, Gianni Bisogno, M.D. ${ }^{\mathrm{c}}$, \\ Davide Biasoni, M.D. ${ }^{\mathrm{d}}$, Renata Boldrini, M.D. ${ }^{\mathrm{e}}$, Paola Collini, M.D. ${ }^{\mathrm{f}}$, Massimo Conte, M.D. ${ }^{\mathrm{g}}$, \\ Patrizia Dall'Igna, M.D. ${ }^{\mathrm{h}}$, Alessandro Inserra, M.D. ${ }^{\mathrm{i}}$, Fraia Melchionda, M.D. ${ }^{\mathrm{j}}$, \\ Fortunato Siracusa, M.D. ${ }^{k}$, Filippo Spreafico, M.D. ${ }^{a}$, Francesco Barretta, M.Sc. ${ }^{1,1}$, \\ Paolo D'Angelo, M.D. ${ }^{\mathrm{m}, 1}$ \\ ${ }^{a}$ Pediatric Oncology Unit, Fondazione IRCCS Istituto Nazionale dei Tumori, Milano, Italy \\ ${ }^{\mathrm{b}}$ Hematology/Oncology Department, Ospedale Pediatrico Bambino Gesù-IRCCS, Roma, Italy \\ ${ }^{\mathrm{c}}$ Pediatric Unit, University-Hospital of Padua, Padova, Italy \\ ${ }^{\mathrm{d}}$ Pediatric Surgery Unit, Fondazione IRCCS Istituto Nazionale dei Tumori, Milano, Italy \\ ${ }^{\mathrm{e}}$ Pathology Unit, Ospedale Pediatrico Bambino Gesù-IRCCS, Roma, Italy \\ ${ }^{\mathrm{f}}$ Pathology Unit, Fondazione IRCCS Istituto Nazionale dei Tumori, Milano, Italy \\ ${ }^{\mathrm{g}}$ Oncology Unit, Ospedale Pediatrico G. Gaslini, Genova, Italy \\ ${ }^{\text {h }}$ Pediatric Surgery Department, University-Hospital of Padua, Padova, Italy \\ ${ }^{i}$ Pediatric Surgery Department, Ospedale Pediatrico Bambino Gesù-IRCCS, Roma, Italy \\ ${ }^{\mathrm{j}}$ Hematology/Oncology Unit, Ospedale L. Seragnoli, Bologna, Italy \\ ${ }^{\mathrm{k}}$ Pediatric Surgery Department, Università of Palermo, Palermo, Italy \\ ${ }^{1}$ Unit of Clinical Epidemiology and Trial Organization, Fondazione IRCCS Istituto Nazionale dei Tumori, Milano, Italy \\ ${ }^{\mathrm{m}}$ Hematology/Oncology Unit, A.R.N.A.S Civico Di Cristina e Benfratelli, Palermo, Italy
}

Received 20 March 2018; received in revised form 25 May 2018; accepted 2 July 2018

\begin{abstract}
Objectives: We report the results of an Associazione Italiana Ematologia Oncologia Pediatrica (AIEOP) study on the treatment of testicular germ cell tumors (TGCT) with a pediatric PEB (pPEB) regimen (cisplatin $25 \mathrm{mg} / \mathrm{m}^{2}$ daily on days $1-4$; etoposide $100 \mathrm{mg} / \mathrm{m}^{2}$ daily on days $1-4$; bleomycin $15 \mathrm{mg} / \mathrm{m}^{2}$ on day 2 , once per cycle).

Methods and materials: Male patients under 18 years old with malignant TGCT were enrolled for a second national prospective protocol. All patients underwent orchiectomy at diagnosis. Those with Stage I received no chemotherapy; those with Stage II-III disease received three cycles of pPEB; and those with Stage IV received four cycles. After chemotherapy, resection of radiologically-evident residual disease was recommended. The main study end-points were overall survival and relapse-free survival.

Results: Ninety-nine boys from 0.5 to 17.8 years old (median 15.4 years) were evaluable, and staged as follows: 58 Stage I (59\%), 7 Stage II (7\%), 14 Stage III (14\%), and 20 Stage IV (20\%). With a median follow-up of 59 months (range 4-165 months), 5-year relapse-free survival $(95 \% \mathrm{CI})$ was $73 \%(65 \%-83 \%)$ for the whole sample, 65\% (53\%-79\%) for Stage I patients, and $86 \%$ (75\%-98\%) for Stage II-IV patients. Five-year overall survival (95\% CI) was $99 \%$ (97\%-100\%).

Conclusions: We confirmed a good prognosis for malignant TGCT in children and adolescents. Reducing the number of chemotherapy cycles for Stage II-III disease does not seem to negatively affect survival outcomes. ( 2018 Published by Elsevier Inc.
\end{abstract}

Keywords: Children; Adolescents; Germ cell tumors; Testis

\footnotetext{
*Corresponding author. Tel.: +39 0223902588; fax: +390223902648.

E-mail address: monica.terenziani@istitututotumori.mi.it

(M. Terenziani).

${ }^{1}$ Equally contributed.
} 


\section{Introduction}

Testicular germ cell tumors (TGCT) are rare in children, and histologically and genetically similar to extragonadal tumors [1], whereas in adolescents they reveal genetic and clinical patterns similar to the disease in adults. These differences have led to TGCT being classified as type I for children with yolk sac tumor (YST) and/or teratoma (T) or type II for adolescents and young men with other, pure or mixed, sub entities [2]. In a previous Italian study [3], 36 TGCT patients ( $\leq 16$ years old) underwent surgery, with or without radiotherapy and carboplatin-based chemotherapy (CT). Their event-free survival (EFS) and overall survival (OS) were $84.5 \%$ and $100 \%$, respectively. Based on this experience, a new protocol was launched on malignant germ cell tumors by the Associazione Italiana Ematologia Oncologia Pediatrica (AIEOP), entitled "TCGM-AIEOP2004," that extended the age at enrolment from $\leq 16$ years to $\leq 18$ years, and adopted a standard CT combination (cisplatin, etoposide, and bleomycin), in dose adjusted the dosage to limit late effects (pediatric cisplatin-etoposidebleomycin [pPEB]).

\section{Methods}

Patients with TGCT were registered for the protocol as part of the TCGM-AIEOP-2004. The protocol was approved by the local ethical committees.

Patients $\leq 18$ years old were enrolled if they had histologically-proven TGCT (seminoma [Sem] or non-seminoma [non-Sem], including pure forms or combinations of YST, embryonal carcinoma [ECA], choriocarcinoma, Sem, and T), or pathological serum $\alpha$-fetoprotein $(\alpha \mathrm{FP})$ and/or $\beta$-human chorionic gonadotropin ( $\beta$-hCG) levels. Males with pure $\mathrm{T}$, or non-germ-cell component were excluded. Patients were followed up with abdominal ultrasound and chest X-rays, clinical examinations, $\alpha \mathrm{FP}$, and $\beta$-hCG assay as described elsewhere [4]. Staging was done according to the Children's Oncology Group (COG) [5], modified system (Table 1). Centralized pathology review was possible, but not mandatory.

Table 1

Staging according to the children's oncology group modified system

Stage I: tumor limited to testis, completely resected by high inguinal incision; tumor markers negative after appropriate half-life decline; retroperitoneal lymph node(s) negative at imaging; no clinical, radiographic, or histologic evidence of disease beyond the testes.

Stage II: trans-scrotal orchiectomy with tumor violation; microscopical residual or positive lymph nodes $(<2 \mathrm{~cm})$; microscopic disease in scrotum or higher in spermatic cord; tumor markers positive or negative.

Stage III: retroperitoneal lymph node(s) involvement $>2 \mathrm{~cm}$; tumor markers positive or negative.

Stage IV: distant metastases; which may include persistent elevation of the tumor markers.

\subsection{Treatment and response criteria}

Patients underwent initial orchiectomy through a high inguinal incision. Though, a transscrotal approach without tumor violation was not consistent with the protocol, patients treated this way were included. Subsequent treatments depended on disease stage: patients in Stage I with tumor markers returning to normal underwent surveillance alone. The others received a pPEB regimen (cisplatin 25 $\mathrm{mg} / \mathrm{m}^{2}$ daily on days $1-4 \mathrm{~b}$; etoposide $100 \mathrm{mg} / \mathrm{m}^{2}$ daily on days $1-4$; bleomycin $15 \mathrm{mg} / \mathrm{m}^{2}$ on day 2 , once per cycle), every 21 days with 3 cycles for Stages II-III, and 4 cycles for stage IV or persistently pathological markers. After CT, resection of radiologically-evident residual disease was recommended, with unilateral nerve-sparing dissection (RPLND) in the retroperitoneum for cases with a residual mass $>1 \mathrm{~cm}$ along its shorter axis. Bilateral disease was managed surgically, sparing the less-involved testis to avoid castration. Semen collection was suggested before $\mathrm{CT}$, depending on the patient's age.

Response criteria were as reported elsewhere [4]. If marker levels were high at diagnosis, cases were only classified as progressing if tumor growth coincided with further increasing marker levels. Patients with a partial response (PR) and residual tumor underwent surgical exploration, and their histology was classified as fibronecrotic tissue (FNT), residual T, or viable malignant cells (VMC).

\subsection{Statistical analysis}

The end-points were OS and relapse-free survival (RFS) in patients with TGCT. RFS was considered instead of EFS because only one event observed was not a relapse (contralateral tumor). OS and RFS definitions and analyses are provided in the supplementary statistical method [6]. Subgroup analyses were performed by disease stage. The median follow-up was estimated with the reverse Kaplan-Meier method using OS data [7].

Univariable Cox models were performed to investigate the association between RFS (in Stage I patients) and baseline $\alpha \mathrm{FP}$ levels (normal, low, intermediate or high), baseline $\beta$-hCG levels (normal, low, intermediate, or high) [8], age (both $<11$ vs $\geq 11$ and $<15$ vs $\geq 15$ ), primary tumor size (pT2-3 vs pT1), lymphovascular invasion (LVI), ECA, and histology (type II vs type I). Categorical covariates were included using dummy variables. Statistical analyses were performed with SAS (SAS Institute, Cary, North Carolina) and $\mathrm{R}$ software (R Foundation for Statistical Computing, Vienna, Austria).

\section{Results}

From March 2004 to December 2016, 113 cases of TGCT were collected. Fourteen were not eligible (somatic malignancy, adjuvant treatment for Stage I, CT with adult bleomycin, etoposide, cisplatin [BEP] regimen, different 
CT regimen). The median age of the 99 eligible patients was 15.4 years (range: $0.5-17.8$ years): 23 patients were $<11$, and $55 \geq 15$ years old, consistently with previous published series [5,11]. In particular, our series included 23 children under 2 year old, 8 aged between 12 and 14, and 68 aged 15 or older. The median follow-up was 59 months (range: $4-165$ months). Patients were staged as follows: 58 Stage I (59\%); 7 Stage II (7\%), 14 stage III (14\%), and 20 Stage IV (20\%). The histotypes identified were: non-Sem in 98 cases (29 type I, and 69 type II) and Sem in one. Central pathology review was done in 53 cases, confirming the original findings in all but one. Table 2 shows the baseline tumor characteristics.

Stage I: Fifty eight patients (one Sem, 57 non-Sem); 7 patients $(12 \%)$ treated via a trans-scrotal approach without tumor violation. Twenty patients relapsed ( 2 with scrotal violation), and one developed a contralateral tumor 42 months after surgery [9]: most relapses (70\%) involved the retroperitoneal lymph nodes and tumor markers were usually pathological (85\%). Eighteen relapsed patients received 4 cycles of pPEB (plus surgery in 6 cases), 2 received 6 cycles of pPEB (plus surgery in one case). Two patients received a second-line $\mathrm{CT}$, one for second relapse, and one for a chondrosarcoma component emerging at histology. On univariable Cox analysis, $\alpha$ FP levels, $\beta$-hCG levels, and age $[8,10,11]$ were not statistically significant, whereas pT2-3, histology type II, LVI [12], and ECA were unfavorable prognostic factors for RFS (Supplementary Table 1).

Stage II: Seven patients, all given scheduled pPEB. One underwent RPLND due to tumor growth despite markers returning to normal levels; histology revealed $T$. No patients relapsed.

Stage III: Fourteen patients given the scheduled treatment. Four achieved a complete response (CR). Ten patients underwent RPLND. One had an extra CT cycle due to persistently high $\alpha$ FP. Histology identified T in 5 cases, FNT in 4. One patient with bilateral tumor had neoadiuvant $\mathrm{CT}$ before orchiectomy of the most-involved testis plus bilateral RPLND ( $\mathrm{T}$ in the testis and T+VMC in lymph nodes). He relapsed after 15 months (lungs and contralateral testis). One patient relapsed in the diaphragmatic retrocrural lymph nodes with no increase in tumor markers, undergone surgery; histology identified $\mathrm{T}$.

Stage IV: Twenty patients given 4 cycles of pPEB. Ten achieved a CR, 10 a PR. The latter undergone RPLND. Histology revealed $\mathrm{T}$ in 8 cases, and $\mathrm{T}+\mathrm{VMC}$ in two.

Two patients had second surgical procedures. All residual mediastinal and clavicular nodes were removed in one (histology indicated T). Lung metastases were resected in the other (FNT at histology). Eighteen months later, progression of residual left lung disease (with no increase in tumor markers) was documented, and the patient died of surgical complications. The pathology report indicated $\mathrm{T}$.

Table 2

Baseline tumor characteristics overall, and by age at enrollment

\begin{tabular}{|c|c|c|c|c|c|c|c|c|c|c|}
\hline \multirow[t]{3}{*}{ Characteristic } & \multicolumn{2}{|c|}{ All patients } & \multicolumn{8}{|c|}{ Age at enrollment } \\
\hline & \multirow[t]{2}{*}{$\mathrm{n}=99$} & \multirow[t]{2}{*}{$\%(100)$} & \multicolumn{2}{|c|}{$<11$ years } & \multicolumn{2}{|c|}{$\geq 11$ years } & \multicolumn{2}{|c|}{$<15$ years } & \multicolumn{2}{|c|}{$\geq 15$ years } \\
\hline & & & n (23) & $\%(23.2)$ & $\mathrm{n}(76)$ & $\%(76.8)$ & n (44) & $\%(44.4)$ & n (55) & $\%(55.6)$ \\
\hline \multicolumn{11}{|c|}{$\alpha$ FP pathological level at diagnosis ${ }^{\circ}$} \\
\hline High & 6 & 6.1 & 4 & 66.7 & 2 & 33.3 & 5 & 83.3 & 1 & 16.7 \\
\hline Intermediate & 15 & 15.2 & 9 & 60.0 & 6 & 40.0 & 9 & 60.0 & 6 & 40.0 \\
\hline Low & 57 & 57.6 & 8 & 14.0 & 49 & 86.0 & 22 & 38.6 & 35 & 61.4 \\
\hline Normal & 15 & 15.2 & 0 & 0.0 & 15 & 100 & 4 & 26.7 & 11 & 73.3 \\
\hline Unknown & 6 & 6.1 & 2 & 33.3 & 4 & 66.7 & 4 & 66.7 & 2 & 33.3 \\
\hline \multicolumn{11}{|c|}{$\beta$-hCG pathological level at diagnosis ${ }^{\circ}$} \\
\hline High & - & - & - & - & - & - & - & - & - & - \\
\hline Intermediate & 6 & 6.1 & 0 & 0.0 & 6 & 100 & 2 & 33.3 & 4 & 66.7 \\
\hline Low & 44 & 44.4 & 0 & 0.0 & 44 & 100 & 15 & 34.1 & 29 & 65.9 \\
\hline Normal & 42 & 42.4 & 20 & 47.6 & 22 & 52.4 & 22 & 52.4 & 20 & 47.6 \\
\hline Unknown & 7 & 7.1 & 3 & 42.9 & 4 & 57.1 & 5 & 71.4 & 2 & 28.6 \\
\hline \multicolumn{11}{|l|}{ LVI } \\
\hline Yes & 57 & 66.3 & 10 & 17.5 & 47 & 82.5 & 23 & 40.4 & 34 & 59.6 \\
\hline No & 29 & 33.7 & 8 & 27.6 & 21 & 72.4 & 12 & 41.4 & 17 & 58.6 \\
\hline Missing & 13 & 13.1 & 3 & 42.9 & 4 & 57.1 & 9 & 69.2 & 4 & 30.8 \\
\hline \multicolumn{11}{|l|}{ Histology } \\
\hline Type I & 29 & 29.3 & 23 & 79.3 & 6 & 20.7 & 24 & 82.8 & 5 & 17.2 \\
\hline Type II & 70 & 70.7 & 0 & 0.0 & 70 & 100.0 & 20 & 28.6 & 50 & 71.4 \\
\hline \multicolumn{11}{|l|}{ Stage } \\
\hline I & 58 & 58.6 & 21 & 36.2 & 37 & 63.8 & 31 & 53.4 & 27 & 46.6 \\
\hline II & 7 & 7.1 & 0 & 0.0 & 7 & 100 & 0 & 0.0 & 7 & 100 \\
\hline III & 14 & 14.1 & 2 & 14.3 & 12 & 85.7 & 5 & 35.7 & 9 & 64.3 \\
\hline IV & 20 & 20.2 & 0 & 0.0 & 20 & 100 & 8.0 & 40.0 & 12 & 60.0 \\
\hline
\end{tabular}

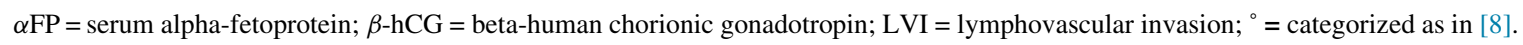


Two patients relapsed in the bone and at primary site. After surgical removal of the latter, histology indicated $\mathrm{T}$.

Table 3 shows the characteristics of relapses in Stage III to IV.

\subsection{Overall and RFS}

Five-year OS (95\% CI) were $99 . \%(97 \%-100 \%)$ overall, $94 \%(83 \%-100 \%)$ in stage IV and $100 \%$ in the others. Five-year RFS (95\% CI) was $73 \%(65 \%-83 \%)$, overall, and $65 \%(53 \%-79 \%), 100 \%, 85 \%(67 \%-100 \%)$, and $82 \%$ $(66 \%-100 \%)$, in Stages I to IV, respectively (Fig 1, panel A and Supplementary Table 2). Twenty, stage II to IV patients achieved a CR with CT, and 21 with CT plus surgery; the 5-year RFS was $86 \%$ (95\% CI: 75\%-98\%; Fig 1, panel B and Supplementary Table 2).

\subsection{Toxicity}

The CT was well tolerated and there were no acute toxic deaths or cases of secondary leukemia. No lung or acoustic nerve impairments emerged during the follow-up. A child fathered by one of the patients is reported in good health.

\section{Discussion}

We describe the second Italian series of TGCT. Compared with the first [3], there was a higher number of cases, especially involving older patients. The OS results were similar. Adolescent cases are probably still under-reported because they may be included in adult and pediatric studies.

Five-year RFS in Stage I patients was $65 \%$, but the omission of adjuvant $\mathrm{CT}$ is not questioned in the pediatric setting [12-15]: surveillance should be offered to all children and adolescents with Stage I disease. RFS in Stage I patients was associated not with age or tumor marker levels, but with pathological features (pTsize, LVI, ECA, type II). LVI and a predominance of ECA are the strongest predictors of recurrence $[16,17]$ in adults, but limited data on this issue are available in pediatric and adolescent series. Cost et al. [18] found occult metastatic disease in $58.3 \%$ of 23 patients with these high-risk factors, and in none of their patients without them. Even in this high-risk group, however, the excellent results obtained after relapses support avoiding adjuvant treatment. Pediatricians worry about the long-term treatment sequela and try to avoid CT for the sake of patients' future health. Cisplatin is measurable in the serum for years after exposure, and detectable in every bodily organ at autopsy [19-21]. The cumulative incidence of serious or life-threatening chronic health conditions in pediatric cancer survivors by the time they are 45 years old is reported as high as $80 \%$, suggesting premature aging as a consequence of cancer therapies [22]. The debate on surveillance, adjuvant CT, and RPLND is still ongoing for adult males with testicular cancer. Surveillance exposes patients to the risk of recurrence, but almost all relapsing patients are rescued with $\mathrm{CT}$, with or without further surgery, so the potential benefit might outweigh the risk. Our patients who relapsed all received 4 cycles of CT, with the associated cumulative morbidity. Their better risk

Table 3

History and characteristics of relapses in patients with stage III and IV tumor

\begin{tabular}{|c|c|c|c|c|c|c|c|}
\hline $\begin{array}{l}\text { Age } \\
\text { (years) }\end{array}$ & $\begin{array}{l}\text { Primary tumor } \\
\text { histology }\end{array}$ & $\begin{array}{l}\text { Stage and markers } \\
\text { at diagnosis }\end{array}$ & $\begin{array}{l}\text { RFS } \\
\text { (months) }\end{array}$ & Site of and markers at relapse & Treatment relapse & Relapse histology & $\begin{array}{l}\text { OS } \\
\text { (months) }\end{array}$ \\
\hline 16 & Type II & $\begin{array}{l}\text { III } \\
\alpha \text { FP: Intermediate } \\
\beta \text {-hCG: } \text { Low }^{\circ}\end{array}$ & 14 & $\begin{array}{l}\text { Retro peritoneal lymph nodes } \\
\text { Markers negative }\end{array}$ & Surgery & Mature teratoma & 127 \\
\hline 16 & Type II & $\begin{array}{l}\text { III (bilateral) } \\
\alpha \text { FP: Low }\end{array}$ & 15 & $\begin{array}{l}\text { Lung } \\
\text { Testis } \\
\text { Markers negative }\end{array}$ & $\begin{array}{l}\text { Orchiectomy } \\
\text { CT } \rightarrow \text { HD-CT }\end{array}$ & ECA & 43 \\
\hline 14 & Type II & $\begin{array}{l}\text { IV } \\
\alpha \text { FP: } \text { High }^{\circ} \\
\beta \text {-hCG: Intermediate }\end{array}$ & 30 & $\begin{array}{l}\text { Retroperitoneal mass } \\
\text { with pancreatic involvement } \\
\text { Markers negative }\end{array}$ & Surgery & Mature teratoma & 34 \\
\hline 17 & Type II & $\begin{array}{l}\text { IV } \\
\alpha \text { FP: Low } \\
\beta \text {-hCG: Low }\end{array}$ & 18 & $\begin{array}{l}\text { Lung } \\
\text { Markers negative }\end{array}$ & Surgery & Mature teratoma & $18^{*}$ \\
\hline 16 & Type I & $\begin{array}{l}\text { IV } \\
\alpha \text { FP: Low }\end{array}$ & 5 & $\begin{array}{l}\text { Bone } \\
\text { Markers data missing }\end{array}$ & CT and RT & Not done & 101 \\
\hline
\end{tabular}

$\mathrm{RFS}=$ relapse-free survival; OS = overall survival; $\alpha \mathrm{FP}=$ alfa-fetoprotein; $\beta$-hCG = beta-human chorionic gonadotropin; $\mathrm{CT}=$ chemotherapy; $\mathrm{HD}-\mathrm{CT}=$ high dose chemotherapy; ECA = embryonal carcinoma; $\mathrm{RT}=$ radiotherapy ${ }^{\circ}=$ categorized as in $[8] ;$ *exitus. 


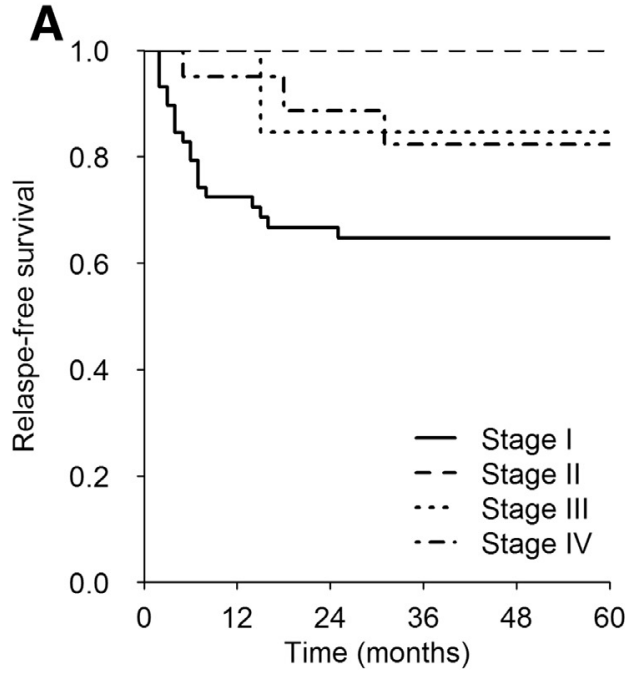

\begin{tabular}{|c|c|c|c|c|}
\hline Stage I 58 & 41 & 34 & 26 & 22 \\
\hline Stage II 7 & 5 & 4 & 4 & 3 \\
\hline Stage III 14 & 14 & 10 & 10 & 9 \\
\hline Stage IV 20 & 17 & 14 & 12 & 11 \\
\hline
\end{tabular}

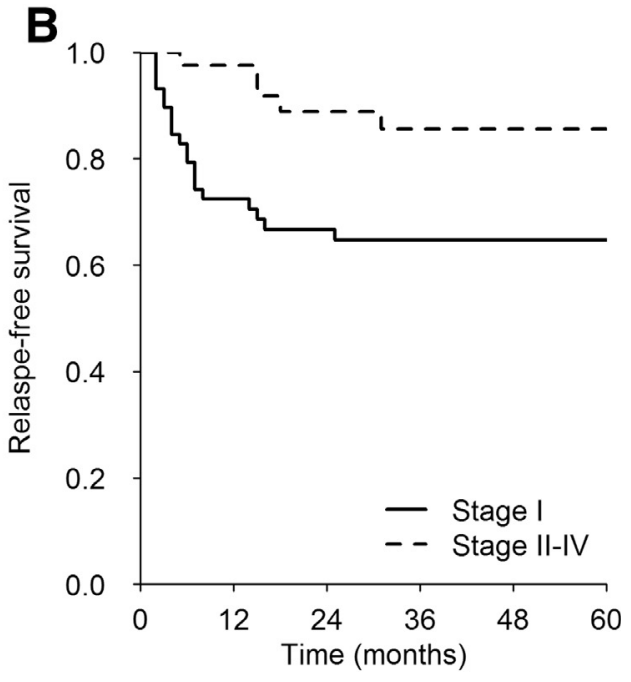

$\begin{array}{rlllll}\text { Stage I } 58 & 41 & 34 & 26 & 22 & 18 \\ \text { Stage II-IV } 41 & 36 & 28 & 26 & 23 & 19\end{array}$

Fig 1. Relapse-free survival curves according to stage (panel A), and with stage II-IV as single group (panel B).

stratification should enable the maximum number of cycles to be administered only to those at highest risk.

Another issue for patients with TGCT concerns their exposure to computed tomography scans for surveillance purposes. Given the value of tumor markers for monitoring purposes and the good prognosis of TGCT, our protocol recommends strict follow-up with markers and ultrasound, adding computed tomography only in selected cases.

Adolescents usually reveal the genetic and clinical patterns typical of non-Sem in adults [23]. After extending the age limit for enrolment in a pediatric protocol, and collecting more older patients, we were surprised to find that age was not statistically significant. Cost et al. [24] suggested a worst EFS for adolescents than for children or adults. Adolescents had more mixed histology, and more aggressive disease, while children had more YST. Adolescents also presented with significantly more advanced disease than children or adults, possibly due to its different histology (though their EFS was worse even after taking histology, stage, and risk into account). The largest population-based comparative analysis conducted on adults and adolescents [25] recently confirmed that adolescents have more advanced disease at diagnosis, but found their OS better OS than in adults, and their EFS much the same. In our series, stage I patients with type I (typically children) did better than those with type II tumors (usually adolescents).

RFS was good in our few patients with Stages II to IV disease, as in other published pediatric series. Mann et al. [15] had a 100\% 5-year EFS in 17 patients treated with carboplatin-based CT (only 3 were between 10 and 16 years old). Lopes et al. [14] extended the age of accrual to 18 years and found a 10-year EFS of $84 \%$ in 32 stages II to III patients (given at least 4 cycles of cisplatin + etoposide), and $64 \%$ in 34 stage IV patients (given at least 4 cycles of cisplatin + etoposide + ifosphamide). The COG had already tried a compressed $\mathrm{PEb}$ regimen (cycles delivered in 3 days with a single dose of bleomycin) instead of standard BEP $[5,11,26]$. We delivered pPEB in 4 days with a single dose of bleomycin and less etoposide, than in the standard (BEP) or compressed $(\mathrm{PEb})$ regimens. These dose reductions did not seem to influence OS and RFS [4], though randomized trials on adult male series found worse results after lower doses of bleomycin and etoposide, and alternative combinations did not achieve better results in terms of survival and toxicity [27]. Fizazi et al. [28] reported a worse survival in patients whose tumor markers dropped slowly after their first BEP cycle. Standard BEP currently remains the gold standard for adult TGCT [29]. The COG's 3 cycles of PEb obtained a 4-year EFS of $83 \%$ in 28 patients $<15$ years old (89\% in Stage II, $80 \%$ in Stage III, and $54 \%$ in Stage IV) [26], which was lower than in two previous studies on patients given 4 cycles $[5,11]$. Their Stage II patients' 4year EFS was actually $100 \%$, but they were all $<11$ years old, and all but one had a YST [5]. The 6-year EFS for patients in Stages III and IV were $100 \%$ and $89 \%$, respectively: this COG series included patients up to 21 years old, but when only those $\geq 15$ were considered, the results were comparable with ours (83\% in stage III and $84 \%$ in stage IV) [11]. All our patients in Stages II to III received 3 cycles of pPEB. This schedule, achieved good survival rates with low cumulative doses of etoposide and bleomycin, and none of the patients have had severe late effects to date. Randomized trials would be necessary to confirm these results. 
This study has some important limitations. It was a single-arm study with a long accrual period due to the rarity of disease and the dispersion of cases between pediatric and adult centers; no stratification criteria were adopted $[8,10]$ other than stage, and some patients could not be included in our analysis because they had received standard BEP at their local center. An international cooperative clinical trial, covering all age groups is ongoing [26].

\section{Conclusions}

Males with TGCT generally have a good outcome with a low burden of CT-related and late sequelae. As pediatric oncologists, we support surveillance for Stage I disease to avoid CT if possible. Efforts should be made to harmonize guidelines and protocols for adolescents with TGCT and to devise a common risk stratification strategy. All patients should be managed by experts at specialized centers [30].

\section{Acknowledgments}

The authors acknowledge Giovanni Cecchetto M.D, for his important contribution.

\section{Disclosure}

This research did not receive any specific grant from funding agencies in the public, commercial or not-for-profit sectors.

\section{Supplementary materials}

Supplementary material associated with this article can be found, in the online version, at doi:10.1016/j.urolonc. 2018.07.001.

\section{References}

[1] Schenider DT, Terenziani M, Cecchetto G, Olson TA. Gonandal and extragonadal germ cell tumors, sex cord stromal and rare gonadal tumors. In: Schenider DT, Brecht IB, Olson TA, Ferrari A, eds. Rare tumors in children and adolescents, Springer-Verlag; 2012:327-402.

[2] Oosterhuis JW, Looijenga LH. Testicular germ-cell tumours in a broader prospective. Nat Rev Cancer 2005;5:210-22.

[3] Lo Curto M, Lumia F, Alaggio R, Cecchetto G, Cecchetto G, Indolfi $\mathrm{P}$, et al. Malignant germ cell tumors in childhood: results of the first Italian cooperative study "TCG91". Med Ped Oncol 2003;41:417-25.

[4] Terenziani M, Bisogno G, Boldrini R, Cecchetto G, Conte M, Boschetti L, et al. Malignant ovarian germ cell tumors in pediatric patients: the AIEOP (Associazione Italiana Ematologia Oncologia Pediatrica) study. Pediatr Blood Cancer 2017;64:e26568.

[5] Rogers PC, Olson TA, Cullen JW, Billmire DF, Marina N, Rescorla F, et al. Treatment of children and adolescents with stage II testicular cancer and stage I and II ovarian malignant germ cell tumors: a pediatric intergroup study-pediatric oncology group 9048 and children's cancer group 8891. J Clin Oncol 2004;22:3563-9.

[6] Kaplan EL, Meier P. Non parametric estimation from incomplete observation. J Am Stat Assoc 1958;53:457-81.
[7] Schemper M, Smith TL. A note on quantifying follow-up studies of failure time. Control Clin Trials 1996;17:343-6.

[8] International Gem Cell Cancer Collaborative Group. International germ cell consensus classification: a prognostic factor-based staging system for metastatic germ cell cancers. J Clin Oncol 1997; 15:594-603.

[9] Terenziani M, Spreafico F, Gotti G, Biasoni D, Piva L, Collini P. Bilateral testicular germ cell tumors. J Pediatr Surg 2014;8:1341.

[10] Frazier AL, Hale JP, Rodriguez-Galindo C, Dang H, Olson T, Murray $\mathrm{MJ}$, et al. Revised risk classification for pediatric extracranial germ cell tumors based on 25 years of clinical trial data from the United Kingdom and United States. J Clin Oncol 2015;33:195-201.

[11] Cushing B, Giller R, Cullen JW, Marina NM, Lauer SJ, Olson TA, et al. Randomized comparison of combination chemotherapy with etoposide, bleomycin, and either high-dose or standard-dose cisplatin in children and adolescents with high-risk malignant: a pediatric intergroup study-pediatric oncology group 9049 and children's cancer group 8882. J Clin Oncol 2004;22:2691-700.

[12] Rescorla FJ, Ross JH, Billmire DF, Dicken BJ, Villaluna D, Davis MM, et al. Surveillance after initial surgery for stage I pediatric and adolescent boys with malignant testicular germ cell tumors: report from the children's oncology group. J Pediatr Surg 2015;50:1000-3.

[13] Gobel U, Schneider DT, Calaminus G, Haas RJ, Schmidt P, Harms D. Germ-cell tumors in children and adolescents. Ann Oncol 2000;11:263-71.

[14] Lopes LF, Macedo CR, Aguiar Sdos S, Barreto JH, Martins GE, Sonaglio V, et al. Lowered cisplatin dose and no bleomycin in the treatment of pediatric germ cell tumors: results of the GCT-99 protocol from the Brazilian germ cell pediatric oncology cooperative group. J Clin Oncol 2016;34:603-10.

[15] Mann JR, Raafat F, Robinson K, Imeson J, Gornall P, Sokal M, et al. The United Kingdom children's cancer study group's second germ cell tumor study: carboplatin, etoposide, and bleomycin are effective treatment for children with malignant extracranial germ cell tumors, with acceptable toxicity. J Clin Oncol 2000;18:3809-18.

[16] Grantham EC, Caldwell BT, Cost NG. Current urologic care for testicular germ cell tumors in pediatric and adolescent patients. Urol Oncol 2016;34:65-75.

[17] Vergouwe Y, Steyerberg EW, Eijkemans MJ, Albers P, Habbema JD. Predictors of occult metastasis in clinical stage I nonseminoma: a systematic review. J Clin Oncol 2003;21:4092-9.

[18] Cost NG, Lubahn JD, Adibi M, Romman A, Wickiser JE, Raj GV. Risk stratification of pubertal children and postpubertal adolescents with clinical stage I testicular nonseminomatous germ cell tumors. J Urol 2014;191:1485-90.

[19] Travis LB, Fossa SD, Schonfeld SJ, McMaster ML, Lynch CF, Storm $\mathrm{H}$, et al. Second cancer among 40,576 testicular cancer patients: focus on long-term survivors. J Natl Cancer Inst 2005;97:1354-65.

[20] Stoneham SJ, Hale JP, Rodriguez-Galindo C, Dang H, Olson T, Murray $\mathrm{M}$, et al. Adolescents and young adults with a "rare" cancer: getting past semantics to optimal care for patients with germ cell tumors. Oncologist 2014;19:689-92.

[21] Chovanec M, Abu Zaid M, Hanna N, El-Kouri N, Einhorn LH, Albany C. Long-term toxicity of cisplatin in germ-cell tumor survivors. Ann Oncol 2017;28:2670-9.

[22] Robison LL, Hudson MM, Survivors of childhood and adolescent cancer: life-long risks and responsibilities. Nat Rev 2014;14:61-70.

[23] Bleyer A. Adolescent and young adult (AYA) oncology: the first A. Pediatr Hematol Oncol 2007;24:325-36.

[24] Cost NG, Lubahn JD, Adibi M, Romman A, Wickiser JE, Raj GV, et al. A comparison of pediatric, adolescent, and adult testicular germ cell malignancy. Pediatr Blood Cancer 2014;61:446-51.

[25] Amini A, Waxweiler TV, Maroni PD, Kessler ER, Cost CR, Greffe BS, et al. Survival outcomes of adolescent and adult patients with non-seminomatous testicular germ cell tumors: a population-based study. J Pediatr Urol 2016;12:405.e1-405.e9. 
[26] Shaikh F, Cullen JW, Olson TA, Pashankar F, Malogolowkin MH, Amatruda JF, et al. Reduced and compressed cisplatin-based chemotherapy in children and adolescents with intermediate-risk extracranial malignant germ cell tumors: a report from the children's oncology group. J Clin Oncol 2017;11:1203-10.

[27] Grimison PS, Stockler MR, Thomson DB, Olver IN, Harvey VJ, Gebski VJ, et al. Comparison of two standard chemotherapy regimens for good-prognosis germ cell tumors: update analysis of a randomized trial. J Natl Cancer Inst 2010;102:1223-62.
[28] Fizazi K, Pagliaro L, Laplanche A, Fléchon A, Mardiak J, Geoffrois L, et al. Personalized chemotherapy based on serum tumor marker decline in poor prognosis germ-cell tumors (GETUG 13): a phase 3, multicentre, randomized trial. Lancet Oncol 2014;15:1442-50.

[29] Hanna NH, Einhorn LH. Testicular cancer-discoveries and updates. N Engl J Med 2014;371:2005-16.

[30] Albany C, Adra N, Snavely AC, Cary C, Masterson TA, Foster RS, et al. Multidisciplinary clinic approach improves overall survival outcomes of patients with metastatic germ cell tumors. Ann Oncol 2018;29:341-6. 